\title{
Protective effect of naringenin against experimental colitis via suppression of Toll-like receptor 4/NF-kB signalling
}

\author{
Wei Dou ${ }^{1,2}$, Jingjing Zhang ${ }^{1,3}$, Aning Sun ${ }^{1,3}$, Eryun Zhang ${ }^{1,3}$, Lili Ding ${ }^{1}$, Subhajit Mukherjee ${ }^{2}$, \\ Xiaohui $\mathrm{Wei}^{1}$, Guixin $\mathrm{Chou}^{4}$, Zheng-Tao Wang ${ }^{1,4_{*}} \dagger$ and Sridhar Mani ${ }^{2} \dagger$ \\ ${ }^{1}$ Shanghai Key Laboratory of Formulated Chinese Medicines and MOE Key Laboratory for Standardization of Chinese \\ Medicines, Institute of Chinese Materia Medica, Shanghai University of Traditional Chinese Medicine, Shanghai 201203, \\ People's Republic of China \\ ${ }^{2}$ Departments of Medicine and Genetics, Albert Einstein College of Medicine, New York 10461, USA \\ ${ }^{3}$ Department of Pharmacognosy, China Pharmaceutical University, Nanjing 210038, People's Republic of China \\ ${ }^{4}$ Shanghai RED Center for Standardization of Traditional Chinese Medicine, Shanghai 201203, People's Republic of China \\ (Submitted 30 July 2012 - Final revision received 13 November 2012 - Accepted 14 November 2012 - First published online 18 March 2013)
}

\section{Abstract}

Naringenin, one of the most abundant flavonoids in citrus, grapefruits and tomatoes, has been used as a traditional anti-inflammatory agent for centuries. However, the molecular mechanism of naringenin in intestinal inflammation remains unknown so far. The present study investigated a molecular basis for the protective effect of naringenin in dextran sulphate sodium-induced murine colitis. Pre-administration of naringenin significantly reduced the severity of colitis and resulted in down-regulation of pro-inflammatory mediators (inducible NO synthase (iNOS), intercellular adhesion molecule-1 (ICAM-1), monocyte chemoattractant protein-1 (MCP-1), cyclo-oxygenase-2 (Cox2), $T N F-\alpha$ and $I L-6$ mRNA) in the colon mucosa. The decline in the production of pro-inflammatory cytokines, specifically TNF- $\alpha$ and IL- 6 , correlated with a decrease in mucosal Toll-like receptor 4 (TLR4) mRNA and protein. Phospho-NF- $\mathrm{B}$ p65 protein was significantly decreased, which correlated with a similar decrease in phospho-IкB $\alpha$ protein. Consistent with the in vivo results, naringenin exposure blocked lipopolysaccharide-stimulated nuclear translocation of NF- $\mathrm{B}$ p 65 in mouse macrophage RAW264.7 cells. In addition, in vitro NF- $\kappa B$ reporter assays performed on human colonic HT-29 cells exposed to naringenin demonstrated a significant inhibition of TNF- $\alpha-$

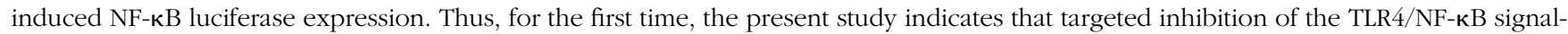
ling pathway might be an important mechanism for naringenin in abrogating experimental colitis.

Key words: Dextran sulphate sodium-induced colitis: Toll-like receptor 4: NF-kB: Signalling pathways: Naringenin

Naringenin (4',5,7-trihydroxyflavanone), one of the most abundant flavonoids in citrus, grapefruits and tomatoes, has been reported to exhibit interesting pharmacological activities, such as anti-oxidation, anti-inflammation and antitumour $^{(1,2)}$. A recent investigation suggested that naringenin co-administration significantly ameliorated the extent of intestine oedema in a mice model of dextran sulphate sodium (DSS)-induced colitis $^{(3)}$; however, the underlying mechanism has not yet been investigated.

The molecular signalling pathways governing intestinal inflammation are varied; however, a distinct pathway of inflammation comes from signals originating from the interaction of the gut commensal bacteria and the host mucosa ${ }^{(4,5)}$. Indeed, the exact nature of these signals, as to one that initiates host inflammation, remains debated. It is clear that invariably there is dysbiosis in gut inflammatory diseases (e.g. inflammatory bowel disease (IBD)) ${ }^{(6)}$, and along with dysbiosis, there is dysregulation of pattern-recognition receptors that recognise pathogen-associated molecular patterns $^{(7)}$. Together, these are essential triggers of release of pro-inflammatory cytokines in the gut, which has paved the path towards discovery of pharmacological targets of $\mathrm{IBD}^{(8-10)}$. One such pattern-recognition receptor, Toll-like receptor 4 (TLR4), a key receptor for commensal recognition in gut innate immunity, is over-expressed in inflamed colonocytes and is the subject of therapeutics (target inhibition)

\footnotetext{
Abbreviations: Cox2, cyclo-oxygenase-2; DSS, dextran sulphate sodium; iNOS, inducible NO synthase; IBD, inflammatory bowel disease; MCP-1, monocyte chemoattractant protein-1; TLR4, Toll-like receptor 4; UC, ulcerative disease.
}

*Corresponding author: Dr Z.-T. Wang, fax +86 21 51322519, email wangzht@hotmail.com

† Z.-T. Wang and S. Mani contributed equally to the paper. 
in $\operatorname{IBD}^{(11,12)}$. As one of the innate immune receptors, TLR 4 signals through recruitment of the adaptor proteins myeloid differentiation primary response gene 88 (MyD88) and Toll/ interleukin 1 receptor domain-containing adaptor protein inducing IFN- $\beta$ (TRIF) ${ }^{(13)}$. MyD88 signalling results in NF-кB activation, while TRIF signalling activates both NF-кB and interferon-regulatory factor 3 . Thereby, TLR4-induced signalling leads to activation of NF-кB and interferon-regulatory factor 3, followed by a pleiotropic gene expression involved in immune and inflammatory responses ${ }^{(14)}$. Thus, it is proposed that many therapeutic targets that abrogate intestinal inflammation might transect with the TLR4 signalling pathway ${ }^{(11,15)}$. Based on the key role that TLR4 plays in enterocyte inflammation, we investigated the role of naringenin in inhibiting TLR4-linked NF- $\mathrm{B}$ signalling pathway in DSS-induced murine colitis.

\section{Materials and methods}

\section{Materials and animals}

Naringenin (molecular weight 272.25 Da, HPLC $\geq 98 \%$ ) was obtained from the Shanghai R\&D Center for Standardization of Traditional Chinese Medicine, Shanghai, China. Mouse macrophage RAW 264.7 cells and human colorectal carcinoma HT-29 cells were purchased from the American Type Culture Collection and maintained in a normal state according to the culture manual. For in vivo studies, naringenin stock solution was prepared in $0.5 \%(\mathrm{w} / \mathrm{v})$ methylcellulose and administered orally to mice at a dose of $50 \mathrm{mg} / \mathrm{kg}$ per $\mathrm{d}$. Naringenin dosing was similar to previous reports ${ }^{(16,17)}$. As vehicle control, all mice received an equivalent volume (compared with experimental groups) of $0 \cdot 5 \%(\mathrm{w} / \mathrm{v})$ methylcellulose solution. Healthy 8- to 10-week-old female C57BL/6 mice (20 (SD 2) g) were obtained from the Laboratory Animal Center of Shanghai University of Traditional Chinese Medicine, and studies were performed in accordance with the guidelines approved by the Animal Ethics Committee of the Shanghai University of Traditional Chinese Medicine, Shanghai. All mice were housed under a specific pathogen-free facility at the Shanghai University of Traditional Chinese Medicine, under the same laboratory conditions of temperature $\left(25 \pm 2^{\circ} \mathrm{C}\right)$ and lighting (12 h light-12 h dark cycle) and were given free access to standard laboratory chow (containing 10\% fat, 70\% carbohydrates and $20 \%$ protein by energy, supplied by the Shanghai SLAC Experimental Animal Company Limited) and tap water.

\section{Experimental design}

Mouse IBD studies were performed as described previously $^{(18)}$. The experiment lasted for $10 \mathrm{~d}$. Mice were distributed into four groups ( $n$ 10-15 mice per group) based on age (8+ and 9+ weeks, for each round of mouse IBD studies. Mouse IBD studies were repeated twice) and body weight (randomly distributed among four groups): group 1 , vehicle controls were administered $100 \mu \mathrm{l}$ of $0.5 \%(\mathrm{w} / \mathrm{v})$ methylcellulose orally once per $\mathrm{d}$; group 2, naringenin at a dose of $50 \mathrm{mg} / \mathrm{kg}$ of body weight via oral administration once per $\mathrm{d}$; group 3, $100 \mu \mathrm{l}$ of $0.5 \%(\mathrm{w} / \mathrm{v})$ methylcellulose by oral administration once per $\mathrm{d}$ and $4 \%(\mathrm{w} / \mathrm{v})$ DSS (molecular weight 36000$50000 \mathrm{Da}$; MP Biomedicals) in drinking-water from days 4 to 10; group 4, received naringenin by oral administration ( $50 \mathrm{mg} / \mathrm{kg}$ of body weight) $3 \mathrm{~d}$ prior to DSS treatment and continued till the end of DSS treatment. Total volume orally administered was identical for each group.

\section{Colitis evaluation}

Mice were monitored daily for signs of body movement, body weight, diarrhoea and bloody stools. Bloody diarrhoea events were evaluated clinically by inspection of anal discharge, and a percentage value was determined based on the number of animals with this condition at any given point of time ${ }^{(19)}$. After killing the mice under anaesthesia, the entire colon was excised and placed on an ice plate and cleaned of fat and mesentery. The length of each colon specimen was measured. The distal and proximal colons were taken and fixed in $10 \%(\mathrm{w} / \mathrm{v})$ buffered formalin for $24 \mathrm{~h}$ at room temperature and embedded in paraffin and stained with haematoxylin-eosin for histological evaluation. Histological damage was assessed as a combined score of inflammatory cell infiltration (score 0-3) and mucosal damage (score 0-3) using a method previously described ${ }^{(20)}$. For inflammatory cell infiltration in the colon mucosa, rare inflammatory cells (mononuclear infiltrates) in the lamina propria were counted as 0 ; increased numbers of inflammatory cells, including neutrophils in the lamina propria, as 1 ; confluence of inflammatory cells, extending into the submucosa as 2 ; and a score of 3 was given for transmural extension of the inflammatory cell infiltration. For epithelial damage, absence of mucosal damage was counted as 0 , discrete focal lymphoepithelial lesions were counted as 1 , mucosal erosion/ulceration was counted as 2 and a score of 3 was given for extensive mucosal damage and extension through deeper structures of the bowel wall. The two sub-scores were added and the combined histological score ranged from 0 (no changes) to 6 (extensive cell infiltration and tissue damage).

\section{Western blot analysis}

Colon tissues were disrupted by homogenisation on ice and centrifuged at $4^{\circ} \mathrm{C}(12000 \mathrm{~g}, 15 \mathrm{~min})$. The supernatants were collected and protein concentrations were determined. Equal amounts of protein $(40 \mu \mathrm{g} / \mathrm{lane})$ were separated on $10 \%$ SDS-PAGE and transferred to nitrocellulose membrane. Membranes were blocked in 5\%(w/v) skimmed milk and incubated with antibodies against mouse TLR4 (sc-293072, 1:1000; Santa Cruz Biotechnology), phospho-p65 (\#3033, 1:1000; Cell Signaling Technology, Inc.), phospho-ІкВ $\alpha$ (\#2859, 1:1000; Cell Signaling) and $\beta$-actin (\#4970, 1:2000; Cell Signaling). Blots were then washed three times with PBS containing $0 \cdot 1 \%(\mathrm{w} / \mathrm{v})$ Tween-20 and incubated with horseradish peroxidase-conjugated secondary antibodies (Santa Cruz). Blots were again washed with PBS containing $0 \cdot 1 \%(\mathrm{w} / \mathrm{v})$ Tween-20, and then developed by enhanced chemiluminescence detection regents (Amersham). The protein bands were quantified by the average ratios of integral 
optic density following normalisation to the housekeeping gene $\beta$-actin expression.

\section{RNA analysis}

RNA was extracted from colon tissues using TRIzol reagent (Invitrogen). Quantitative real-time PCR was performed using complementary DNA generated from $3 \mu \mathrm{g}$ total RNA with the SuperScript II Reverse transcriptase kit (Invitrogen). The primer sequences used in PCR amplification are as follows: 5'-TTCAGAGCCGTTGGTGTATC-3'/5'-CCCATTCCAGGTAGGTGTTT- $3^{\prime}$ for TLR4, 5'-GGGAATCTTGGAGCGAGTTG-3'/5'-GTGAGGGCTTGGCTGAGTGA-3' for inducible NO synthase (iNOS), 5'-CGCTGTGCTTTGAGAACTGT-3'/ 5'-AGGTCCTTGCCTACTTGCTG-3' for intercellular adhesion molecule-1 (ICAM-1), 5'-AAGTTGACCCGTAAATCTGA-3'/ 5'-TGAAAGGGAATACCATAACA- $3^{\prime}$ for monocyte chemoattractant protein-1 (MCP-1), 5'-GAAGTCTTTGGTCTGGTGCCT-3'/ 5'-GCTCCTGCTTGAGTATGTCG-3' for cyclo-oxygenase-2 (Cox2), '-CGTGGAACTGGCAGAAGAGG-3'/5'-AGACAGAAGAGCGTG GTGGC- $3^{\prime}$ for TNF- $\alpha, 5^{\prime}$-ACCACGGCCTTCCCTACTTC- $3^{\prime} / 5^{\prime}$-CA TTTCCACGATTTCCCAGA- $3^{\prime}$ for IL-6, 5'-CAGCCTTCCTTCTTG GGTAT-3'/ $5^{\prime}$-TGGCATAGAGGTCTTTACGG- $3^{\prime}$ for $\beta$-actin. PCR were carried out using SYBR Premix ExTaq Mix (Takara Biotechnology) in an ABI Prism 7900HT Sequence Detection System (Applied Biosystems). Thermal cycler parameters were as follows: one cycle of $95^{\circ} \mathrm{C}$ for $30 \mathrm{~s}$, forty cycles of denaturation $\left(95^{\circ} \mathrm{C}, 5 \mathrm{~s}\right)$ and combined annealing/extension $\left(60^{\circ} \mathrm{C}, 30 \mathrm{~s}\right)$. Gene expression changes were calculated by the comparative $C_{\mathrm{t}}$ method and the values were normalised to endogenous reference $\beta$-actin.

\section{Determination of TNF- $\alpha$ and IL- 6 levels}

Mid-colon segments were homogenised in ice-cold physiological saline. The homogenates were centrifuged at $3000 \mathrm{~g}$ for $10 \mathrm{~min}$ and the supernatants were assayed for the determination of levels of the cytokines. The levels of each cytokine were evaluated using ELISA kits according to the manufacturer's protocols (R\&D Systems), and the results are expressed in $\mathrm{pg} / \mathrm{mg}$ of protein in each sample.

\section{$N F-\kappa B$ nuclear translocation immunofluorescence}

RAW264.7 cells were seeded in eight chamber slides (BD Biosciences) at a density of $5 \times 10^{4}$ cells per well. Cells were allowed to adhere at $37^{\circ} \mathrm{C}$ overnight and naringenin ( $25 \mu \mathrm{mol} / \mathrm{l}$ ) was added for $2 \mathrm{~h}$. Then, cells were overnight stimulated with lipopolysaccharide $(2 \mu \mathrm{g} / \mathrm{ml}$; Sigma-Aldrich) and fixed with $4 \%(\mathrm{w} / \mathrm{v})$ paraformaldehyde solution at $20^{\circ} \mathrm{C}$ for $10 \mathrm{~min}$. After washing in PBS, cells were permeabilised with $0 \cdot 3 \%(\mathrm{w} / \mathrm{v})$ Triton $\mathrm{X}-100$ in PBS at room temperature for $20 \mathrm{~min}$. After incubation in blocking buffer containing $0 \cdot 1 \%(\mathrm{w} / \mathrm{v})$ Triton $\mathrm{X}-100,1 \%(\mathrm{w} / \mathrm{v})$ bovine serum albumin and $3 \%(\mathrm{w} / \mathrm{v})$ donkey serum, cells were then incubated with rabbit NF-кB p65 antibody (\#8242, 1:50; Cell Signaling) overnight at $4^{\circ} \mathrm{C}$. After washing in PBS, cells were further incubated with Alexa Fluor 488-conjugated donkey anti-rabbit
IgG (A-21 206, 1:500; Invitrogen) at room temperature for $45 \mathrm{~min}$. In order to stain the nuclei, we added $1 \mu \mathrm{g} / \mathrm{ml}$ of $4^{\prime}, 6-$ diamidino-2-phenylindole (DAPI; Invitrogen) in PBS at room temperature. Fluorescence photographs were obtained using an Olympus CKX41 fluorescence microscope (Olympus Company).

\section{$N F-\kappa B$ luciferase reporter assay}

HT-29 cells were seeded in a twenty-four-well plate at a density of $1.5 \times 10^{5}$ cells/well at $1 \mathrm{~d}$ before transfection. The cells were transfected with $0 \cdot 8 \mu \mathrm{g}$ of pGL4.32 (luc2P/NF- $\mathrm{kB}$ $\mathrm{RE} /$ Hygro) vector (Promega) using lipofectamine 2000 reagent (Invitrogen). The pGL4.32 plasmid is a NF- $\mathrm{B}$ reporter vector. It contains NF- $\mathrm{B}$ response elements and the firefly luciferase gene. At $12 \mathrm{~h}$ after the transient transfection, the cells were incubated with or without naringenin (1, 10 and $25 \mu \mathrm{mol} / \mathrm{l})$ for $2 \mathrm{~h}$, then treated with TNF- $\alpha(20 \mathrm{ng} / \mathrm{ml}$; Cell Signaling) for an additional $5 \mathrm{~h}$. At the termination of the experiments, cells were washed once with PBS, then lysed in $0 \cdot 1 \mathrm{ml} 1 \times$ passive lysis buffer (Promega). Cell-free lysates were obtained by centrifugation at $10000 \mathrm{~g}$ for $2 \mathrm{~min}$ at $4^{\circ} \mathrm{C}$. The effects of naringenin and $\mathrm{TNF}-\alpha$ on the activation of $\mathrm{NF}-\kappa \mathrm{B}$ promoter in transfected cells were determined by luciferase activity. Luciferase activity in cell lysate was quantified using a luciferase assay system (Promega) and a Glomax 20/20 luminometer (Promega). The results were presented as relative light units and data were expressed as fold values of control cells. Measurements were performed by calculating the average of quadruplicate samples of two independent experiments.

\section{Statistical analysis}

Data are expressed as the means and standard deviations. Statistical significance was analysed using a one-way ANOVA analysis followed by an independent $t$ test. Statistical significance was considered when the $P$ value was less than 0.05 .

\section{Results}

\section{Naringenin pre-administration attenuated dextran sulphate sodium-induced experimental colitis}

There was no weight loss observed in mice receiving vehicle or naringenin alone (groups 1 and 2, respectively). The body weight of mice in group 3 dramatically decreased from day 3 onwards following DSS treatment. The mice receiving both DSS and naringenin (group 4) exhibited less significant weight loss than did the group 3 mice (Fig. 1(a)). Diarrhoea symptoms appeared on or shortly after day 3. At days 3-7, all the mice on the DSS-only treatment (group 3) experienced both diarrhoea and bloody diarrhoea, whereas none of the mice receiving vehicle or naringenin alone (groups 1 and 2, respectively) exhibited diarrhoea at any point during the study. By day 10, all the group 3 mice were euthanised due to critical weight loss. In contrast, the mice receiving both DSS and naringenin (group 4) exhibited less diarrhoea and bloody diarrhoea than did the group 3 mice (Fig. 1(b)). 
(a)

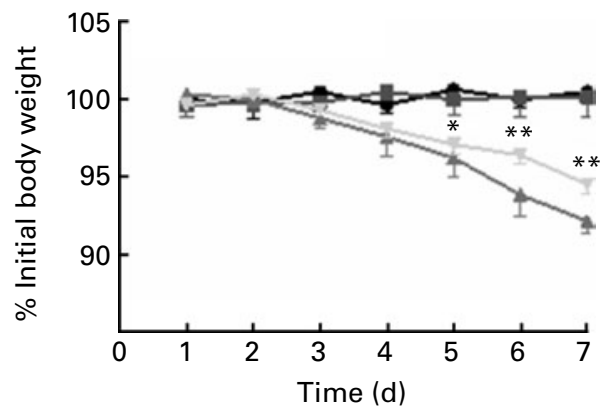

(b)

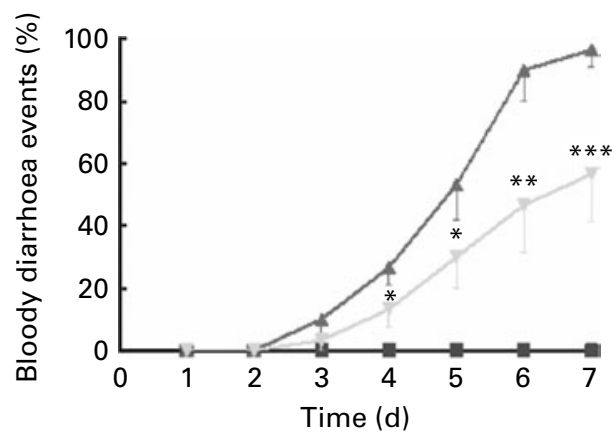

(c) 10

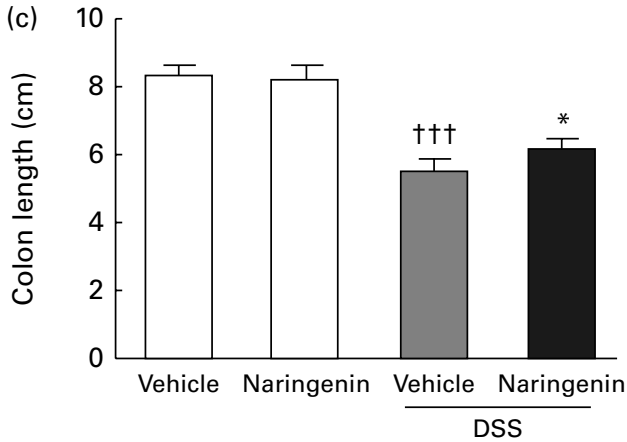

(d)

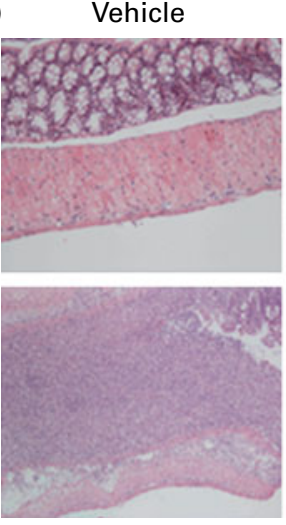

DSS+vehicle

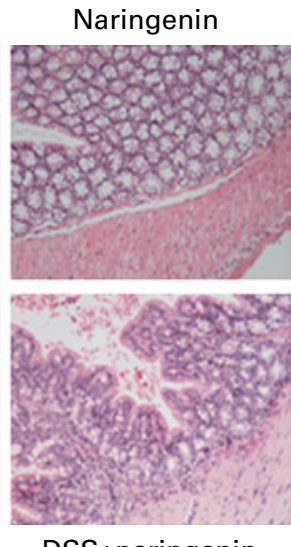

DSS+naringenin

(e)

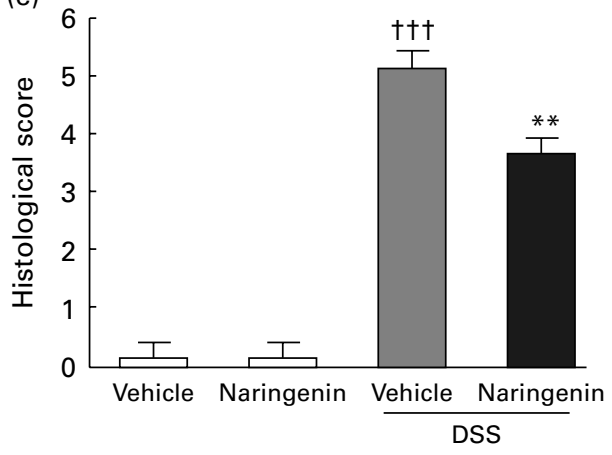

Fig. 1. Protective role of naringenin against dextran sulphate sodium (DSS)-induced colitis in mice. (a) Body weight changes following DSS induction of colitis. Data plotted as percentage of basal body weight. (b) The occurrence of bloody diarrhoea. Mice were evaluated for the occurrence of bloody diarrhoea following DSS administration. Data plotted as percentage of total mice that had bloody diarrhoea on different days (point of time) of DSS treatment. (c) Colon length. (d) Histological sections of mice exposed to DSS and/or naringenin showed healthy colon crypt structure for both vehicle treatment and naringenin treatment, but highly disrupted tissues in the DSS-only treatment group. In contrast, naringenin provided in combination with DSS protected the colon from DSS-induced damage. Original magnification 100x. (e) Histological score of the distal colon. The distal colon is shown for the analyses of haematoxylin-eosin staining and pathohistological examination and scoring. Values are means and standard deviations of $n 20$ vehicle-treated mice, $n 20$ naringenin-treated mice, $n 28$ DSStreated mice and $n 29$ naringenin+DSS-treated mice represented by vertical bars. Mean values were significantly different compared with DSS-treated group: ${ }^{*} P<0.05,{ }^{* *} P<0.01,{ }^{* * *} P<0.001$. †††Mean values were significantly different compared with normal vehicle-treated group $(P<0.001)$. - - Vehicle; $\rightarrow-$, naringenin; $\rightarrow$, DSS+vehicle; $\rightarrow$, DSS+ naringenin.

Colon shortening is an indirect marker of colonic inflammation $^{(21)}$. After $7 \mathrm{~d}$ of treatment with DSS in drinkingwater, there was a significant shortening $(P=0.038)$ of the colon length of mice in group $3(5.5(\mathrm{SD} 0.4) \mathrm{cm}, n$ 22) compared with the mice receiving both DSS and naringenin (group $4,6 \cdot 2(\mathrm{SD} 0.3) \mathrm{cm}, n$ 28). This indicates that the oral administration of naringenin significantly ameliorated the symptom of colon shortening (Fig. 1(c)). Examination and scoring of colonic tissue samples from each group established that naringenin protected mouse mucosal epithelium from DSS-induced damage. Mice treated with vehicle or naringenin alone exhibited intact crypt-villus structures and epithelial layer. DSS administration resulted in a paucity of intact crypt-villus structures and large inflammatory exudates across the thickness of the bowel wall. By contrast, naringenin administration to DSS-exposed mice resulted in significant protection of the colon crypt structures and less severe histological inflammation (Fig. 1(d) and (e)). 


\section{Naringenin inhibited Toll-like receptor $4 \mathrm{mRNA}$ and protein expression}

Growing evidence suggests that the TLR4/NF- $\mathrm{B}$ signalling pathway plays a critical role in the pathogenesis of IBD. Therefore, targeted inhibition of the TLR 4 signalling pathway in recent years has become a therapeutic strategy for $\mathrm{IBD}^{(22,23)}$. To determine the effect of naringenin on TLR 4 repression, quantitative real-time PCR and Western blot analyses were carried out. The results demonstrated that mRNA (Fig. 2(a)) and protein (Fig. 2(b) and (c)) expression of

(a)

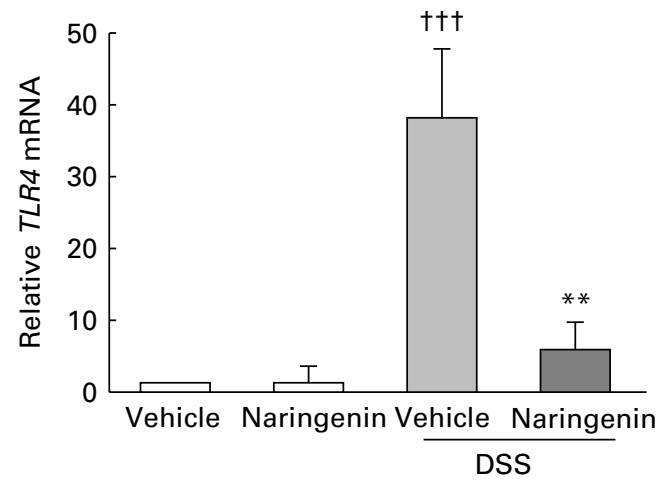

(b)

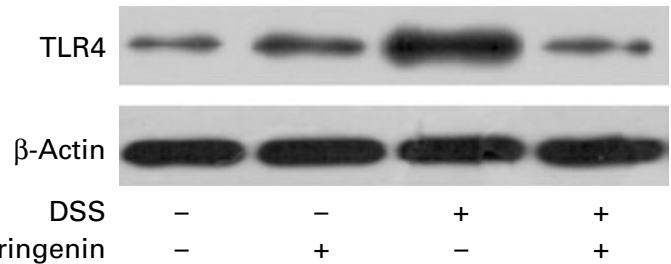

(c)

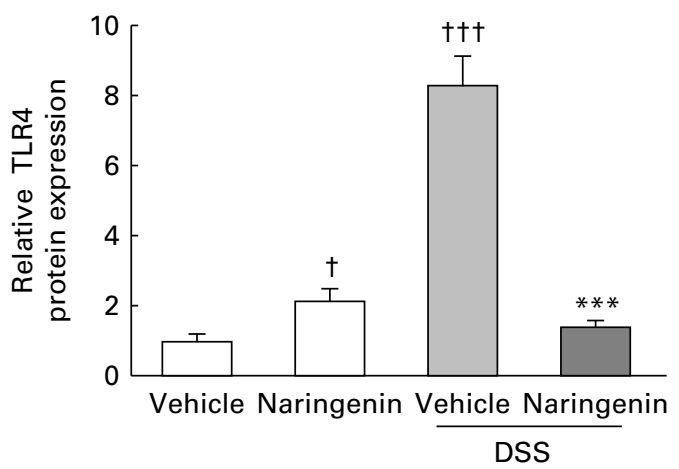

Fig. 2. Effect of naringenin on the expression of Toll-like receptor 4 (TLR4) mRNA and protein in the colon of dextran sulphate sodium (DSS)-induced colitis mice. (a) The mRNA expression of TLR4 was assessed by quantitative real-time PCR in mid-colon samples isolated from mice ( $n 6$ per group) treated with vehicle, naringenin, DSS or naringenin + DSS. Experimental conditions were as described in the Materials and methods. Expression was normalised to $\beta$-actin, and each bar represents the means and standard deviations of triplicates of two independent experiments. (b) Mice ( $n 6$ per group) were killed after $7 \mathrm{~d}$ of $4 \%(\mathrm{w} / \mathrm{v})$ DSS exposure, and total protein $(40 \mu \mathrm{g})$ from mid-colon samples was loaded. Western blot was performed with anti-TLR4 (sc-293072, 1:1000) antibody. A representative experiment from three independent experiments is shown. (c) Quantification of the TLR4 protein expression was performed by densitometric analysis of the blot. Values are means and standard deviations of three independent experiments represented by vertical bars. Mean values were significantly different compared with DSS-treated group: ${ }^{* *} P<0.01,{ }^{\star \star *} P<0.001$. Mean values were significantly different compared with vehicle-treated group: $\dagger P<0.05$, $\dagger+\dagger P<0.001$.
TLR4 were significantly induced in the colon mucosa after 7 d DSS treatment compared with the normal vehicle-treated group. The relative increase in mRNA and protein expression of TLR4 after DSS treatment was significantly less in mice pretreated with naringenin $(P<0 \cdot 01)$. The data indicate that naringenin might provide protection from DSS-induced colitis through suppression of TLR4 signalling.

\section{Naringenin treatment blocked NF- $\kappa B$ activation in vivo and in vitro}

$\mathrm{NF}-\kappa \mathrm{B}$ is viewed as a master switch in the regulation of inflammation and immunity. As a transcription factor, NF- $\kappa \mathrm{B}$ controls an array of pro-inflammatory genes involved in the inflammatory signalling cascade ${ }^{(24,25)}$. Based on this rationale, we hypothesised that the anti-inflammatory effect of naringenin in response to DSS-induced colitis correlated with blockade of NF- $\mathrm{BB}$ activation. A significant increase $(P<0.01)$ in the protein expression of phospho-p65 was observed in colonic tissues of the DSS-induced model group (Fig. 3(a) and (b)). Furthermore, the degradation and phosphorylation of $\mathrm{I} \kappa \mathrm{B} \alpha$ was induced $(P<0 \cdot 001)$ in colonic tissues of DSS-exposed mice compared with controls (Fig. 3(a) and (b)). By contrast, administration of naringenin reduced phospho-p65 expression in DSS-induced colitis, and the phosphorylation/degradation of $\mathrm{I} \kappa \mathrm{B} \alpha$ was effectively suppressed $(P<0 \cdot 01)$. In accordance with the in vivo data presented in Fig. 3(a) and (b), naringenin inhibited NF- $\mathrm{kB}$ p 65 nuclear translocation, as indicated in lipopolysaccharide $(2 \mu \mathrm{g} / \mathrm{ml})$-induced mouse macrophage RAW264.7 cells (Fig. 3(c)). On the other hand, induction of NF-кB-mediated luciferase activity in human colonic HT-29 cells by the inflammatory mediator, TNF- $\alpha(20 \mathrm{ng} / \mathrm{ml})$, was inhibited by naringenin in a dose-dependent manner, reaching 80 (SD 13) \% inhibition at $25 \mu \mathrm{mol} / 1 \quad(P<0.001)$ relative to control cells (Fig. 3(d)). These results indicate that naringenin significantly blocked the NF- $\mathrm{KB}$ signalling pathway in experimental colitis by suppressing ІкВ $\alpha$ phosphorylation/degradation, blocking NF-кB p65 nuclear translocation and inhibiting NF-кBmediated transcriptional activity.

\section{Naringenin inhibited mRNA expression of pro-inflammatory mediators}

To further determine the impact of naringenin on NF- $\kappa \mathrm{B}$ signalling, we investigated the expression levels of representative downstream signalling genes involved in NF-кB activation. Quantitative real-time PCR analyses of several NF- $\mathrm{B}$ target pro-inflammatory mediator genes were carried out. The results showed that mRNA expression of $i N O S, I C A M-1$, $M C P-1, \operatorname{Cox} 2, T N F-\alpha$ and $I L-6$ was remarkably induced $(P<0.001)$ in inflamed colons of mice exposed to DSS (group 3). In contrast, the increase in inflammatory regulators and mediators (iNOS, ICAM-1, MCP-1, Cox2, TNF- $\alpha$ and IL-6) following DSS treatment was significantly decreased $(P<0.01)$ in mice receiving naringenin administration (Fig. 4(a)-(f)). The results indicate that naringenin ameliorated 
(a)
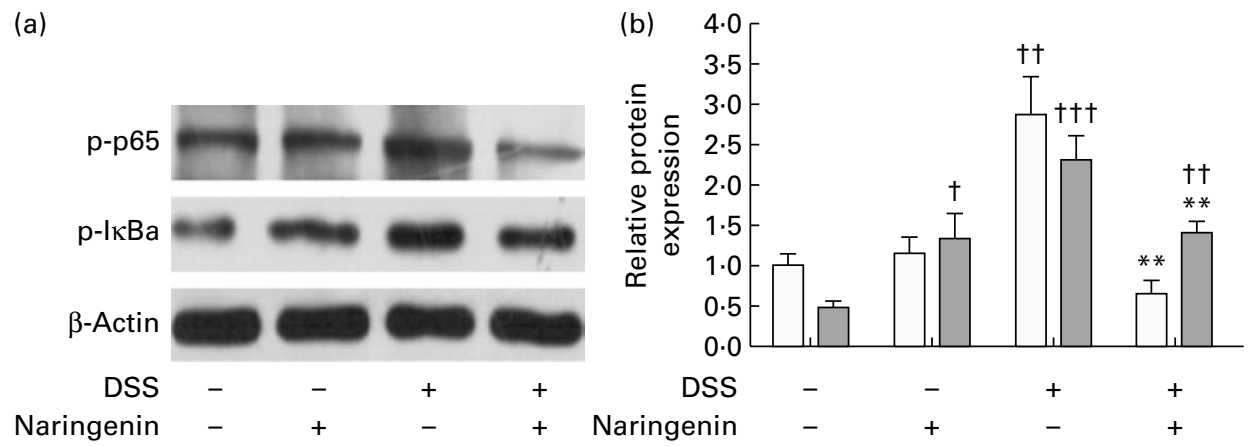

(c)

DAP
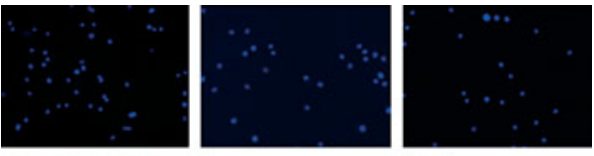

NF-kB p65
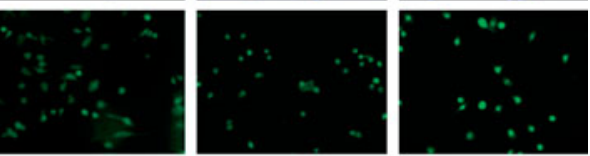

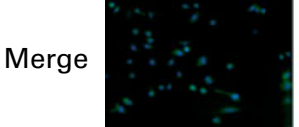

Vehicle

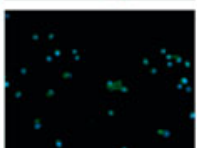

LPS

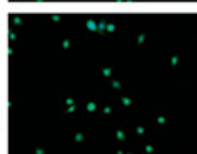

LPS+

(d)

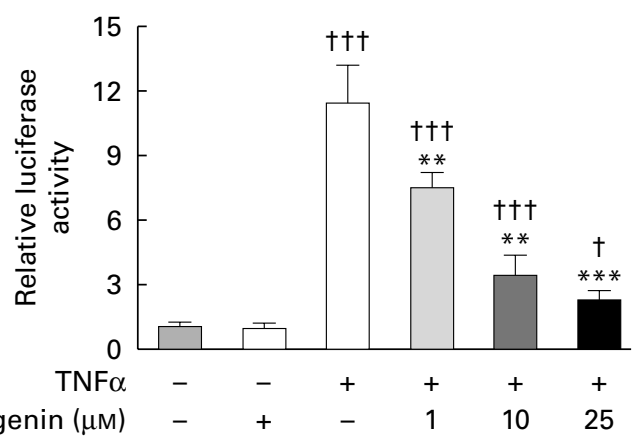

Fig. 3. Effect of naringenin on the suppression of NF-kB activity in vivo and in vitro. (a) Mice ( $n 6$ per group) were killed after $7 \mathrm{~d}$ of $4 \%$ dextran sulphate sodium (DSS) exposure, and total protein $(40 \mu \mathrm{g})$ from mid-colon samples was loaded. Western blot was performed with anti-phospho-p65 (p-p65 ( $\square$ ); \#3033, 1:1000) and anti-phospho-IкB $\alpha\left(\mathrm{p}-\mathrm{I}_{\kappa} \mathrm{B} \alpha(\square)\right.$; \#2859, 1:1000) antibodies. One representative experiment from three independent experiments is shown. (b) Quantification of the p-p65 and p-1кB $\alpha$ protein expression was performed by densitometric analysis of the blot. Values are means and standard deviations of three independent experiments represented by vertical bars. (c) RAW264.7 cells were pre-treated with or without naringenin $(25 \mu \mathrm{mol} / \mathrm{l})$ for $2 \mathrm{~h}$ prior to lipopolysaccharide (LPS) $(2 \mu \mathrm{g} / \mathrm{ml})$ treatment for an additional $12 \mathrm{~h}$. NF-кB p65 localisation was observed under a fluorescence microscope (magnification $200 \times)$ using an anti-NF-кB p65 antibody (\#8242, 1:50) followed by an Alexa 488-conjugated detection antibody (A-21 206, 1:500). $n$ 3. (d) HT-29 cells were transfected with pGL4.32 (luc2P/NF$\mathrm{\kappa B}-\mathrm{RE} / \mathrm{Hygro})$ and then treated with TNF- $\alpha(20 \mathrm{ng} / \mathrm{ml})$ for $5 \mathrm{~h}$. For pre-treatment, cells were treated with naringenin $(1,10$ or $25 \mu \mathrm{mol} / \mathrm{l})$ for $2 \mathrm{~h}$ prior to TNF- $\alpha$ exposure. Cells were lysed and the lysate was analysed using a luciferase assay system. NF-kB promoter-driven luciferase activity was expressed as fold values of control cells (designated as 1). Values are means and standard deviations of quadruplicates of two independent experiments represented by vertical bars. Mean values were significantly different compared with the DSS-treated or TNF- $\alpha$-treated group: ${ }^{* \star} P<0.01,{ }^{* \star \star} P<0.001$. Mean values were significantly different compared with the vehicle-treated group: $\uparrow P<0.05, \dagger^{\dagger} P<0.01$, $\dagger_{\dagger} P<0.001$.

DSS-induced colitis, which correlated with suppression of NF- $\mathrm{B}$ signalling.

\section{Naringenin reduced the production of TNF- $\alpha$ and IL-6 in colon}

A significant increase $(P<0 \cdot 001)$ in the content of TNF- $\alpha$ and IL-6 was observed in mice exposed to DSS (group 3) when compared with control mice (groups 1 and 2). Treatment with naringenin resulted in a reduction $(P<0 \cdot 01)$ in the levels of TNF- $\alpha$ and IL- 6 in mice receiving both DSS and naringenin (group 4) compared with DSS treatment model group (group 3) (Table 1). The data indicate that amelioration of inflammation in DSS-treated mice by naringenin treatment correlated with repression of pro-inflammatory cytokines.

\section{Discussion}

IBD consists of two distinct entities, Crohn's disease and ulcerative disease (UC). The main difference between 

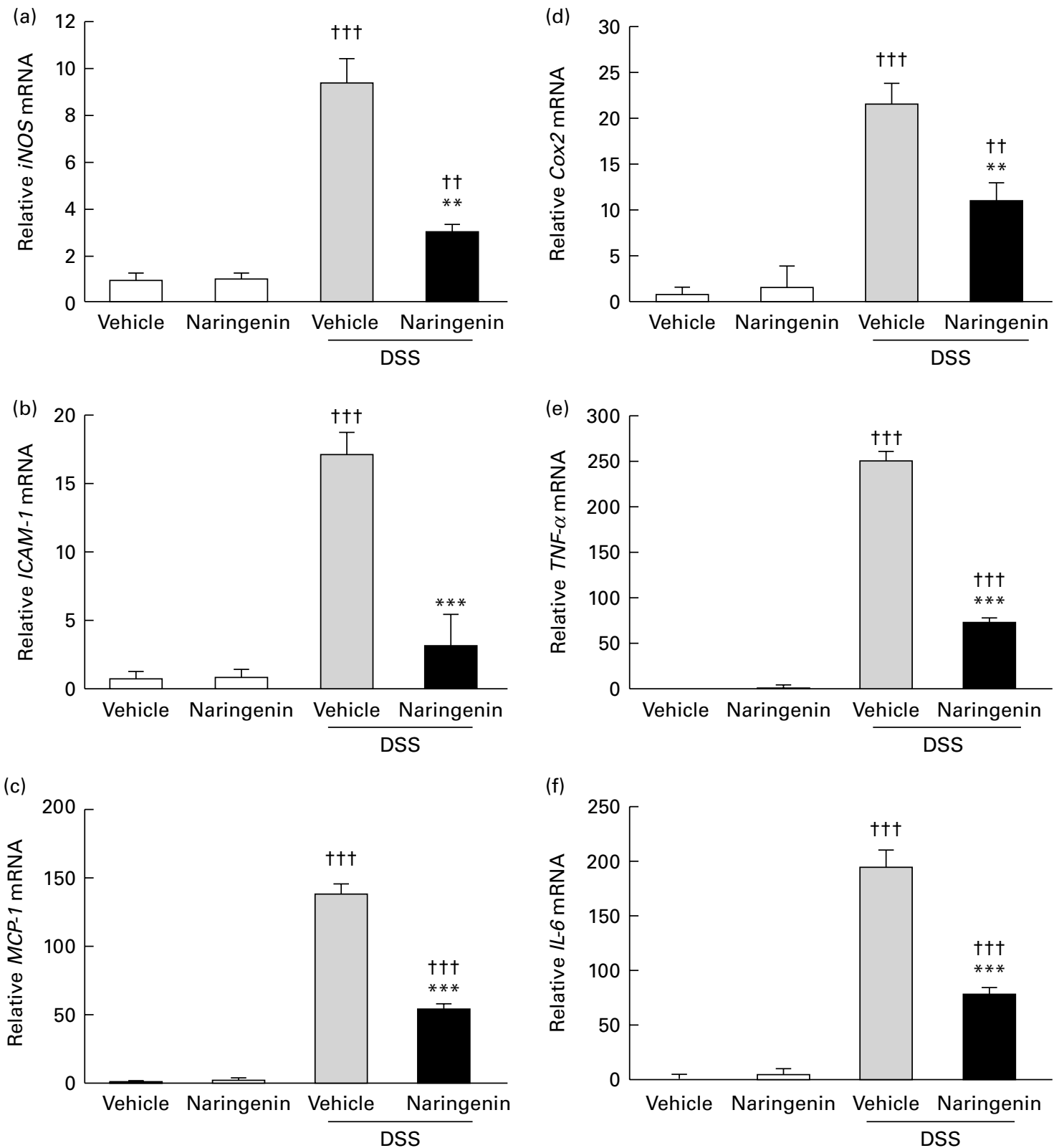

Fig. 4. Effect of naringenin on the mRNA expression of pro-inflammatory mediator genes in the colon of dextran sulphate sodium (DSS)-induced colitis mice. The mRNA expression of (a) inducible NO synthase (iNOS), (b) intercellular adhesion molecule-1 (ICAM-1), (c) monocyte chemoattractant protein-1 (MCP-1), (d) cyclo-oxygenase-2 (Cox2), (e) TNF- $\alpha$ and (f) IL- 6 was assessed by quantitative real-time PCR in mid-colon samples isolated from mice ( $n 6$ per group) treated with vehicle, naringenin, DSS or naringenin + DSS. Experimental conditions were as described in the Materials and methods. Expression was normalised to $\beta$-actin, and values are means and standard deviations of triplicates of two independent experiments represented by vertical bars. Mean values were significantly different compared with the DSS-treated group: ${ }^{* *} P<0.01$, ${ }^{* *} P<0.001$. Mean values were significantly different compared with the vehicle-treated group: $\dagger \dagger P<0.01, \dagger^{\dagger} \dagger P<0.001$

Crohn's disease and UC is the location and nature of the inflammatory changes. Crohn's disease can affect any part of the gastrointestinal tract, from mouth to anus (skip lesions), although a majority of the cases start in the terminal ileum. $\mathrm{UC}$, in contrast, is restricted to the colon and the rectum (continuous lesions). Microscopically, UC is restricted to the mucosa (epithelial lining of the gut), while Crohn's disease affects the whole bowel wall (transmural lesions) ${ }^{(26,27)}$. DSS, a heparin-like polysaccharide, has been widely used to induce both acute and chronic colitis in mouse models, with typical characteristics resembling human $\mathrm{UC}^{(28,29)}$. The present study used an acute model of IBD by administration of DSS in drinking-water. The inflammation was mainly localised to the colon with features resembling human UC, such as ulceration, epithelial damage, mucosal inflammatory cellular infiltration and lymphoid hyperplasia ${ }^{(30,31)}$. The present results demonstrated that naringenin significantly abrogated colitis in a DSS-induced murine colitis model, and the beneficial effect of naringenin treatment could be linked, at least in part, to the inhibition of TLR4 protein and NF- $\mathrm{KB}$ activity, the 
Table 1. The effect of naringenin on the production of colonic TNF- $\alpha$ and IL-6 in dextran sulphate sodium (DSS)-induced colitis miceł (Mean values and standard deviations of triplicates of two independent experiments)

\begin{tabular}{|c|c|c|c|c|}
\hline \multirow[b]{2}{*}{ Group } & \multicolumn{2}{|c|}{$\begin{array}{l}\mathrm{TNF}-\alpha(\mathrm{pg} / \mathrm{mg} \\
\text { protein) }\end{array}$} & \multicolumn{2}{|c|}{$\begin{array}{l}\text { IL-6 }(\mathrm{pg} / \mathrm{mg} \\
\text { protein) }\end{array}$} \\
\hline & Mean & SD & Mean & SD \\
\hline Vehicle & $20 \cdot 8$ & 1.9 & 34.8 & 3.7 \\
\hline Naringenin & $27 \cdot 7$ & 2.5 & $41 \cdot 1$ & $2 \cdot 6$ \\
\hline DSS+vehicle & $184 \cdot 3 \dagger$ & $16 \cdot 1$ & $244 \cdot 7 \dagger$ & $13 \cdot 8$ \\
\hline DSS+naringenin & $79 \cdot 4^{\star \star \star}$ & $6 \cdot 8$ & $112 \cdot 9^{* *}$ & 11.4 \\
\hline
\end{tabular}

Mean values were significantly different compared with the DSS-treated group ${ }^{\star \star} P<0.01,{ }^{\star \star \star} P<0.001$.

† Mean values were significantly different compared with the vehicle-treated group $(P<0.001)$.

$\ddagger$ Segments of mid-colon samples from mice ( $n 6$ per group) were excised and homogenised. The supernatants were assayed for the determination of the levels of TNF- $\alpha$ and IL- 6 using the ELISA method (R\&D Systems).

down-regulation of expression of inflammatory mediators (iNOS, ICAM-1, MCP-1 Cox2, TNF- $\alpha$ and IL-6) and the inhibition of production of inflammatory cytokines (TNF- $\alpha$ and IL-6).

It is well-documented that NF- $\mathrm{B}$ plays a pivotal role in the pathogenesis of IBD. Excess or inappropriate activation of NF- $\mathrm{KB}$ has been observed in human $\operatorname{IBD}^{(30,32,33)}$ and in the murine colitis model ${ }^{(28,31)}$. Inhibition of $\mathrm{NF}-\kappa \mathrm{B}$ activation with a specific p65 antisense oligonucleotide is an effective strategy in preventing experimental models of IBD $^{(34)}$ and in blocking inflammatory cytokine production in IBD patients ${ }^{(35,36)}$. The NF- $\kappa$ B protein family consists of five members that include $\mathrm{p} 50$ and $\mathrm{p} 65$. These proteins form homoand hetero-dimers, of which the p50/p65 heterodimer is the predominant NF- $\mathrm{B}$ complex in most cells. In the absence of an inflammation-inducing stimulus, p50/p65 remains in an inactive state in the cytoplasm, forming a ternary complex with the inhibitory protein $\mathrm{I} \kappa \mathrm{B} \alpha$. Upon stimulation, $І \kappa \mathrm{B} \alpha$ is rapidly phosphorylated by $\mathrm{I} \mathrm{B}$ kinase, ubiquitinated and targeted for proteosome-mediated degradation. These events, thus, allow for the translocation of NF-кB p50/p65 to the nucleus, where it may bind with specific sequences located in the promoter of target genes and activate gene transcription ${ }^{(30)}$. NF- $\kappa \mathrm{B}$ signalling is now considered a pivotal mechanism for the regulation of immune and inflammatory responses by controlling the transcription of inflammatory cytokine genes ${ }^{(30)}$. Thereby, NF- $\mathrm{KB}$ activation is believed to be an important step in the development of human IBD $^{(37)}$. Inhibition of NF- $\mathrm{BB}$ activation is associated with reduced colonic inflammation ${ }^{(38)}$. Many of the drugs used to treat human IBD (e.g. Sulfasalazine, infliximab and anti-TNF- $\alpha$ ) inhibit $\mathrm{NF}-\kappa \mathrm{B}$ activation ${ }^{(39,40)}$. It has also been reported that naringenin protects mice from asthma by preventing NF- $\mathrm{B}$ activation $^{(41)}$. The present study confirms that naringenin protects mice from colitis by inhibiting NF- $\kappa \mathrm{B}$ activation. Consistent with the in vivo data, our in vitro evaluation of $\mathrm{NF}-\kappa \mathrm{B}$ activity suggested a direct role of naringenin on blockade of lipopolysaccharide-stimulated NF-кB p65 nuclear translocation and $\mathrm{TNF}-\alpha$-induced $\mathrm{NF}-\mathrm{\kappa} \mathrm{B}$ promoter luciferase expression. Due to a central role of NF- $\mathrm{B}$ in inflammation, the blockade of NF- $\mathrm{B}$ activation is thought to correspond to the breakage of the inflammatory signalling cascade ${ }^{(42)}$. Indeed, we found that administration of naringenin not only inhibited NF- $\mathrm{BB}$ activity, but also reduced the production of inflammatory cytokines (TNF- $\alpha$ and IL-6), down-regulated inflammatory mediators (iNOS, Cox2, ICAM-1 and MCP-1) and limited the inflammatory (histological) response. Together, these molecular changes result in significant amelioration of DSS-induced colitis.

Among many upstream signalling proteins involved in NF-кB activation, TLR4 plays a critical role ${ }^{(43)}$. As an innate immune receptor, TLR4 activates NF- $\mathrm{B}$ through recruitment of the adaptor proteins MyD88 and TRIF, which leads to subsequent induction of NF- $\mathrm{kB}$ signalling genes, such as iNOS, Cox2, matrix metalloproteinase 9 (MMP-9), ICAM-1, MCP-1, TNF- $\alpha$, $I L-1, I L-6, I L-8, I L-15$ and $I L-27^{(30,44)}$. Furthermore, TLR4 is up-regulated and NF- $\mathrm{KB}$ is activated during DSS-induced colitis in mice ${ }^{(15,22,30)}$. Recent studies indicated that Lactobacillus suntoryeus, a gut commensal, blocks inflammatory mediators (Cox2, TNF- $\alpha$, IL-1 and IL-6) through suppression of TLR4linked NF- $\mathrm{KB}$ activation in mice with 2,4,6-trinitrobenzene sulfonic acid-induced colitis ${ }^{(45)}$. In the present study, TLR4 was up-regulated in the colonic mucosa from mice with DSSinduced colitis; however, the up-regulation of TLR4 was significantly inhibited by naringenin administration. Indeed, there are preclinical strategies targeting TLR 4 activity directly, which also result in significant abrogation of intestinal inflammation ${ }^{(11,46)}$. Thus, in light of the available literature on TLR4 and IBD, the present results support the hypothesis that naringenin appears to exert its effect in ameliorating DSS-induced colitis through blockade of the TLR4-linked NF- $\mathrm{BB}$ signalling pathway.

Other pathways, distinct from TLR4 and NF-кB, are also involved in the pathogenesis of IBD. For instance, recently we demonstrated that baicalein, a natural flavonoid and intestine-specific activator of human and mouse pregnane $\mathrm{X}$ receptor, abrogated DSS-induced colitis through a cdx2mediated pregnane $\mathrm{X}$ receptor activation pathway ${ }^{(18)}$. Shi et $a l .{ }^{(41)}$ showed that naringenin attenuated allergen-induced murine airway inflammation through NF- $\mathrm{B}$ inhibition. Hämäläinen et $a l{ }^{(47)}$ suggested that naringenin exposure blocked lipopolysaccharide-induced nuclear translocation of $\mathrm{NF}-\kappa \mathrm{B}$ in the mouse macrophage RAW264 and reduced iNOS expression. However, until recently, there has been no published evidence associating an interaction of TLR 4 and naringenin or the rationale of the NF- $\mathrm{B}$ pathway underlying the anti-colitis effect of naringenin. To our knowledge, for the first time, the present study demonstrates that TLR4-linked NF-кB signalling inhibition is an important mechanism underlying naringenin's anti-colitic effect in vivo. These results may give insight into the further evaluation of naringenin as a food supplement in the treatment of human IBD.

\section{Acknowledgements}

The present study was supported by the National Natural Science Foundation of China (81150040, U1032604), the Natural Science Foundation of Shanghai (12ZR1431400), the National Institutes of Health Grant RO1CA127231 (S. M.), the Damon Runyon Foundation Clinical Investigator Award 
(CI 1502) (S. M.) and the Albert Einstein College of Medicine. Author contributions are as follows: W. D. participated in study concept and design, acquisition of data, and analysis and interpretation of data; J. Z. aided in analysis and interpretation of data, acquisition of data, statistical analysis; and technical support; A. S. and E. Z. provided technical support, and aided in acquisition of data; L. D. participated in analysis and interpretation of data, and provided technical support; S. M. aided in study concept and design and critical review of the manuscript; $\mathrm{X}$. W. aided in critical review of the manuscript for important intellectual content; G. C. provided material support and aided in critical review of the manuscript; Z.-T. W. provided material support, technical support, and aided in study supervision, administrative and obtained funding; S. M. aided in study concept and design, analysis and interpretation of compiled data, drafting of the manuscript and critical revision of the manuscript for important intellectual content. The authors have no conflicts of interest to declare.

\section{References}

1. Park HY, Kim GY \& Choi YH (2012) Naringenin attenuates the release of pro-inflammatory mediators from lipopolysaccharide-stimulated BV2 microglia by inactivating nuclear factor- $\mathrm{KB}$ and inhibiting mitogen-activated protein kinases. Int J Mol Med 30, 204-210.

2. Yadav VR, Prasad S, Sung B, et al. (2011) The role of chalcones in suppression of NF-кB-mediated inflammation and cancer. Int Immunopharmacol 11, 295-309.

3. Maria Inês Amaro, João Rocha, Helder Vila-Real, et al. (2009) Anti-inflammatory activity of naringin and the biosynthesised naringenin by naringinase immobilized in microstructured materials in a model of DSS-induced colitis in mice. Food Res Int 42, 1010-1017.

4. Cucchiara S, Stronati L \& Aloi M (2012) Interactions between intestinal microbiota and innate immune system in pediatric inflammatory bowel disease. J Clin Gastroenterol 46, S64-S66.

5. Neurath MF \& Travis SP (2012) Mucosal healing in inflammatory bowel diseases: a systematic review. Gut 61, $1619-1635$

6. Mazmanian SK, Round JL \& Kasper DL (2008) A microbial symbiosis factor prevents intestinal inflammatory disease. Nature 453, 620-625.

7. Saunders SP, Barlow JL, Walsh CM, et al. (2010) C-type lectin SIGN-R1 has a role in experimental colitis and responsiveness to lipopolysaccharide. J Immunol $\mathbf{1 8 4}$, $2627-2637$

8. Levin A \& Shibolet O (2008) Toll-like receptors in inflammatory bowel disease-stepping into uncharted territory. World $J$ Gastroenterol 14, 5149-5153.

9. Spiller R \& Lam C (2011) The shifting interface between IBS and IBD. Curr Opin Pharmacol 11, 586-592.

10. Fukata M \& Abreu MT (2008) What are Toll-like receptors and what role may they have in IBD? Inflamm Bowel Dis Suppl. 2, S90-S92.

11. Ungaro R, Fukata M, Hsu D, et al. (2009) A novel Toll-like receptor 4 antagonist antibody ameliorates inflammation but impairs mucosal healing in murine colitis. Am J Physiol Gastrointest Liver Physiol 296, G1167-G1179.

12. Heimesaat MM, Fischer A, Jahn HK, et al. (2007) Exacerbation of murine ileitis by Toll-like receptor 4 mediated sensing of lipopolysaccharide from commensal Escherichia coli. Gut 56, 941-948.

13. Núñez Miguel R, Wong J, Westoll JF, et al. (2007) A dimer of the Toll-like receptor 4 cytoplasmic domain provides a specific scaffold for the recruitment of signalling adaptor proteins. PLoS One 2, e788.

14. Lin S, Yin Q, Zhong Q, et al. (2012) Heme activates TLR4mediated inflammatory injury via MyD88/TRIF signaling pathway in intracerebral hemorrhage. J Neuroinflammation 9, 46.

15. Fiorotto R, Scirpo R, Trauner M, et al. (2011) Loss of CFTR affects biliary epithelium innate immunity and causes TLR4-NF-кB-mediated inflammatory response in mice. Gastroenterology 141, 1498-1508.

16. Kannappan S, Palanisamy N \& Anuradha CV (2010) Suppression of hepatic oxidative events and regulation of eNOS expression in the liver by naringenin in fructoseadministered rats. Eur J Pharmacol 645, 177-184.

17. Ortiz-Andrade RR, Sánchez-Salgado JC, Navarrete-Vázquez $\mathrm{G}$, et al. (2008) Antidiabetic and toxicological evaluations of naringenin in normoglycaemic and NIDDM rat models and its implications on extra-pancreatic glucose regulation. Diabetes Obes Metab 10, 1097-1104.

18. Dou W, Mukherjee S, Li H, et al. (2012) Alleviation of gut inflammation by $\mathrm{Cdx} 2 / \mathrm{Pxr}$ pathway in a mouse model of chemical colitis. PLoS One 7, e36075.

19. Wallace BD, Wang H, Lane KT, et al. (2010) Alleviating cancer drug toxicity by inhibiting a bacterial enzyme. Science 330, 831-835.

20. Siegmund B, Lehr HA, Fantuzzi G, et al. (2001) IL-1 $\beta$ converting enzyme (caspase-1) in intestinal inflammation Proc Natl Acad Sci U S A 98, 13249-13254.

21. Okayasu I, Hatakeyama S, Yamada M, et al. (1990) A novel method in the induction of reliable experimental acute and chronic ulcerative colitis in mice. Gastroenterology $\mathbf{9 8}$, 694-702.

22. Liu L, Li YH, Niu YB, et al. (2010) An apple oligogalactan prevents against inflammation and carcinogenesis by targeting LPS/TLR4/NF-кB pathway in a mouse model of colitis-associated colon cancer. Carcinogenesis 31, $1822-1832$

23. Teng X, Xu LF, Zhou P, et al. (2009) Effects of trefoil peptide 3 on expression of TNF-alpha, TLR4, and NF-kappaB in trinitrobenzene sulphonic acid induced colitis mice. Inflammation 32, 120-129.

24. Zhang DK, Cheng LN, Huang XL, et al. (2009) Tetrandrine ameliorates dextran sulfate sodium-induced colitis in mice through inhibition of nuclear factor-kappa B activation. Int J Colorectal Dis 24, 5-12.

25. Baeuerle PA \& Henkel T (1994) Function and activation of NF- $\mathrm{KB}$ in the immune system. Annu Rev Immunol $\mathbf{1 2}$ $141-153$.

26. Huang BL, Chandra S \& Shih DQ (2012) Skin manifestations of inflammatory bowel disease. Front Physiol 3, 13.

27. van der Marel S, Majowicz A, van Deventer S, et al. (2011) Gene and cell therapy based treatment strategies for inflammatory bowel diseases. World $J$ Gastrointest Pathophysiol 2, 114-122.

28. Shah YM, Ma X, Morimura K, et al. (2007) Pregane X receptor activation ameliorates DSS-induced inflammatory bowel disease via inhibition of NF-kappaB target gene expression. Am J Physiol Gastrointest Liver Physiol 292, G1114-G1122.

29. Masubuchi Y \& Horie T (2004) Endotoxin-mediated disturbance of hepatic cytochrome $\mathrm{P} 450$ function and development of endotoxin tolerance in the rat model of dextran sulfate 
sodium-induced experimental colitis. Drug Metab Dispos 32 , $437-441$

30. Siddique I \& Khan I (2011) Mechanism of regulation of $\mathrm{Na}-\mathrm{H}$ exchanger in inflammatory bowel disease: role of TLR-4 signaling mechanism. Dig Dis Sci 56, 1656-1662.

31. Singh K, Chaturvedi R, Barry DP, et al. (2011) The apolipoprotein E-mimetic peptide COG112 inhibits NF-kappaB signaling, proinflammatory cytokine expression, and disease activity in murine models of colitis. I Biol Chem 286, 3839-3850.

32. Andresen L, Jørgensen VL, Perner A, et al. (2005) Activation of nuclear factor kappaB in colonic mucosa from patients with collagenous and ulcerative colitis. Gut 54, 503-509.

33. Schreiber S, Nikolaus S \& Hampe J (1998) Activation of nuclear factor kappa B infammatory bowel disease. Gut 42, 477-484.

34. Lawrance IC, Wu F, Leite AZ, et al. (2003) A murine model of chronic inflammation-induced intestinal fibrosis downregulated by antisense NF-kappa B. Gastroenterology 125, $1750-1761$.

35. Hibi $\mathrm{T}$, Inoue $\mathrm{N}$, Ogata $\mathrm{H}$, et al. (2003) Introduction and overview: recent advances in the immunotherapy of inflammatory bowel disease. $J$ Gastroenterol 38, 36-42.

36. Li Z, Zhang de K, Yi WQ, et al. (2008) NF-kappaB p65 antisense oligonucleotides may serve as a novel molecular approach for the treatment of patients with ulcerative colitis. Arch Med Res 39, 729-734.

37. Schottelius AJ \& Baldwin AS Jr (1999) A role for transcription factor NF-kappa B in intestinal inflammation. Int J Colorectal Dis 14, 18-28.

38. Atreya I, Atreya R \& Neurath MF (2008) NF-kappaB in inflammatory bowel disease. J Intern Med 263, 591-596.

39. Zhao W, Song L \& Hongzhu D (2010) Amelioration of dextran sulfate sodium-induced chronic colitis by sulfasalazine salicylazosulfapyridine via reducing NF-kappaB transcription factor p65 recruitment to ICAM-1 gene promoters. Yakugaku Zasshi 130, 1239-1249.

40. Arijs I, Li K, Toedter G, et al. (2009) Mucosal gene signatures to predict response to infliximab in patients with ulcerative colitis. Gut 58, 1612-1619.

41. Shi Y, Dai J, Liu H, et al. (2009) Naringenin inhibits allergeninduced airway inflammation and airway responsiveness and inhibits NF-kappaB activity in a murine model of asthma. Can J Physiol Pharmacol 87, 729-735.

42. Cheng J, Shah YM, Ma X, et al. (2010) Therapeutic role of rifaximin in inflammatory bowel disease: clinical implication of human pregnane $\mathrm{X}$ receptor activation. J Pharmacol Exp Ther 335, 32-41.

43. Andersen V, Christensen J, Ernst A, et al. (2011) Polymorphisms in NF-кB, PXR, LXR, PPAR $\gamma$ and risk of inflammatory bowel disease. World J Gastroenterol 17, 197-206.

44. Joh EH \& Kim DH (2010) Lancemaside A inhibits lipopolysaccharide-induced inflammation by targeting LPS/ TLR4 complex. J Cell Biochem 111, 865-871.

45. Lee JH, Lee B, Lee HS, et al. (2009) Lactobacillus suntoryeus inhibits pro-inflammatory cytokine expression and TLR-4linked NF-kappaB activation in experimental colitis. Int $J$ Colorectal Dis 24, 231-237.

46. Fort MM, Mozaffarian A, Stöver AG, et al. (2005) A synthetic TLR4 antagonist has anti-inflammatory effects in two murine models of inflammatory bowel disease. J Immunol 174, 6416-6423.

47. Hämäläinen $M$, Nieminen R, Vuorela $P$, et al. (2007) Antiinflammatory effects of flavonoids: genistein, kaempferol, quercetin, and daidzein inhibit STAT-1 and NF-kappaB activations, whereas flavone, isorhamnetin, naringenin, and pelargonidin inhibit only NF-kappaB activation along with their inhibitory effect on iNOS expression and NO production in activated macrophages. Mediators Inflamm 2007, 45673. 